\title{
Spor Bilimleri Fakültesi ve İlahiyat Fakültesi Öğrencilerinin Psikolojik Dayanıklılık Düzeylerinin Karşılaştırılması
}

\author{
DOI: $10.26466 /$ opus. 567468
}

*

\section{Tülin Atan* - Saban Ünver**}

${ }^{*}$ Doç. Dr, Ondokuz Mayıs Üniversitesi, Y.D. Spor Bilimleri Fakültesi, Atakum/ Samsun / Türkiye E-Posta: takman@omu.edu.tr ORCID: $\underline{0000-0001-5660-8910}$

** Arş. Gör. Ondokuz Mayıs Üniversitesi, Y.D. Spor Bilimleri Fakültesi, Atakum/ Samsun / Türkiye E-Posta: saban.unver@omu.edu.tr

ORCID: 0000-0001-7378-596X

Öz

Bu çalışmanın amacı Spor Bilimleri ve İlahiyat Fakültesi öğrencilerinin psikolojik dayanıklılık düzeylerini incelenmektir. Çalışmaya Spor Bilimleri Fakültesi'nden 151, İlahiyat Fakültesi'nden 149 olmak üzere toplam 300 öğrenci gönüllü olarak katılmıştır. Çalışmada, araştırmacılar tarafından oluşturulan "Demografik Bilgi Formu" ve katılımciların psikolojik dayanıklılık düzeylerini belirlemek için Friborg ve ark. (2005) tarafindan geliştirilen ve Basım ve Çetin (2011) tarafindan Türkçe'ye uyarlanan Psikolojik Dayanıklılık Ölçeği (PDÖ) kullanılmıştır. Her iki fakülte öğrencilerinin PDÖ toplam puanları fakülte, cinsiyet, sigara veya alkol kullanma ve düzenli olarak spor yapma durumu değiş̧kenlerine göre karşılaştırıldr. Fakülteye değişkenine göre ilahiyat fakültesi öğrencilerinin PDÖ toplam puanlarının spor bilimleri fakültesi öğrencilerin puanından anlamlı düzeyde yüksek olduğu tespit edildi $(p<0.05)$. Kadın öğrencilerin PDÖ toplam puanlarının erkek öğrencilerin puanından anlamlı düzeyde yüksek olduğu tespit edildi $(p<0.05)$. Öğrencilerden sigara veya alkol kullanmayanları PDÖ toplam puanlartnın kullanan öğrencilerin puanından anlaml düzeyde yüksek olduğu tespit edildi $(p<0.05)$. Düzenli spor yapma durumuna göre PDÖ toplam puanlarının farklılaşmadığı tespit edildi ( $p>0.05$ ). Üniversitede eğitim görülen fakültenin, cinsiyetin, sigara veya alkol kullanmanın psikolojik dayanıklllı düzeyini etkilediği sonucuna ulaşıldı. Spor Bilimleri Fakültesi'nde okuyan ve erkek öğrencilerin psikolojik dayanıklılık düzeylerinin yükseltilmesi dolayısıyla zorluklara veya olumsuz durumlara karşı başarılı bir baş edebilme sağlayabilmeleri açısından gerekli desteklerin sağlanması önerilebilir.

Anahtar Kelimeler: Öğrenci, Üniversite, Psikolojik Dayanıklılık 


\title{
Comparison of Psychological Resilience Levels of Faculty of Sport Sciences and Faculty of Theology Students
}

\begin{abstract}
The aim of this study is to examine the psychological resilience levels of Faculty of Sport Sciences and Faculty of Theology students. A total of 300 students, 151 Faculty of Sport Sciences students and 149 Faculty of Theology students, participated in the study voluntarily. In the study, "Demographic Information Form" developed by the researchers and "Psychological Resilience Scale" (PRS) developed by Friborg et al. (2005) and adapted into Turkish by Basım and Çetin (2011) were used to find out the physiological endurance levels of the participants. PRS total scores of the students in both faculties were compared in terms of the variables of faculty, gender, cigarette or alcohol use and doing regular sport. In terms of the variable of faculty, it was found that PRS total scores of the faculty of theology students were significantly higher than those of the faculty of sport sciences students $(p<0.05)$. Female students were found to have significantly higher PRS total scores than male students $(p<0.05)$. Students who were not using cigarette or alcohol were found to have significantly higher PRS total scores than students who did $(p<0.05)$. PRS total scores were not found to differ in terms of the state of doing regular sport ( $p>0.05$ ). It was found that faculty, gender, cigarette or alcohol use influenced psychological resilience level. It can be recommended to give necessary support for students in the Faculty of Sport Sciences and male students to increase their psychological resilience levels so that they can successfully cope with difficulties or negative situations.
\end{abstract}

Keywords: Student, University, Psychological Resilience 


\section{Giriş}

İnsan günlük yaşamı birçok olumsuz durum, duygu ve düşünceyi içinde barındırmaktadır. Yaşanılan ve stres yaratan bu deneyimler, kişilerin ruh hali ve psikolojik durumunda kalıcı bozukluklara yol açabilmektedir. İnsanların bu problemle başa çıkabilmesi onların psikolojik dayanıklılık düzeyine bağlıdır. Kimi insanlar bu sorunla baş edemez ve anksiyete, depresyon gibi kalıcı hasarlarla baş başa kalırken kimi insanlar ise psikolojik sağlamlığın sağladığı içsel destekle bu sorunları aşabilmekte ve normal yaşamlarına dönebilmektedir (Doğan, 2015).

Psikolojik dayanıklılık bir travma, bir tehdit, bir trajedi veya ailesel sorunlar, ciddi sağllk problemleri, işyeri ve maddi sorunlar gibi önemli stres kaynaklarına karşı, kişinin uyum sağlama süreci, kendisini toparlama gücü veya zorlukların üstesinden başarılı biçimde gelme yeteneği olarak tanımlanmaktadır. Aynı zamanda psikolojik dayanıklılık, psikolojik sağlamlık ya da kendini toparlama gücü gibi farklı isimlerle ele alınmaktadır (Gürgan 2010; Karaırmak 2006; Basım ve Çetin 2011). Psikolojik sağlamlık, ciddi uyum ve gelişme tehditlerine ve zor yaşam koşullarına rağmen başarılı bir şekilde normal işlevselliğe dönebilme olarak tanımlanmaktadır (Masten, 2001). Psikolojik dayanıklılık, bireyin değişen durumlara tepki göstermede esnek olması ve olumsuzluktan duygusal deneyimlerle çıkarak kendini toparlamak olarak tanımlanmış çok boyutlu bir kavramdır (Tugade ve Fredrickson, 2004).

Bu konuda yapılmış çalışmalarda psikolojik dayanıklılık kavramı farklı araştırmacılar tarafından benzer şekilde tanımlanmıştır. Örneğin; Gizir (2007), zorlu yaşam olayları karşısında ya da belirli riskler altında başarılı bir baş etme, Cencirulo (2001), bireylerin stresli yaşam olaylarında kendilerine olumlu bakış açısı kazanabilmeleri, Holahan ve Moos (1985), psikolojik dayanıklılı̆̆ fiziksel ve psikolojik zorlanmalar karşısında yaşama uyum sağlama, olarak ifade etmişlerdir.

Bu bilgilerden hareket ederek tanımlama yapacak olursak, psikolojik dayanıklılık bir sorunla veya sıkıntıyla karşılaşıldığında bu zorluklar karşısında başarılı bir baş edebilme özelliği olarak önümüze çıkmaktadır. Toplumsal alanda çok boyutlu bir olgu olarak karşımıza çıkan spor, bireysel, ekonomik ve sosyal yönleriyle sağlıklı bireylerin yetişmesinde, halk 
sağlığının korunmasında, ekonominin gelişmesinde, toplumsal barışın tesis edilmesinde, kişiler arası uyumun geliştirilmesinde çok önemli bir konuma sahiptir. Dolayısıyla bu çalışmanın amacı, bu denli olumlu etkileri olan bir olgunun yoğun olduğu spor bilimleri fakültesinde öğrenim gören öğrenciler ile ilahiyat fakültesinde öğrenim gören üniversite öğrencilerinin psikolojik dayanıklılık düzeylerini fakülte ve bazı değişkenlere göre karşılaştırmaktır.

\section{Materyal Metot}

Bu çalışmaya Ondokuz Mayıs Üniversitesi Spor Bilimleri Fakültesi'nde okuyan $(\mathrm{n}=151)$ yaş ortalaması $22,12 \pm 2,33$ yıl ve İlahiyat Fakültesi'nde okuyan ( $\mathrm{n}=149$ ) yaş ortalaması 20,86 $\pm 2,44$ yıl olan toplam 300 öğrenci gönüllü olarak katılmışlardır.

\section{Veri Toplama Araci}

Araştırmada veri toplama aracı olarak araştırmacılar tarafından geliştirilen "Demografik Bilgi Formu" ve Spor Bilimleri ve İlahiyat Fakültesi öğrencilerinin psikolojik dayanaklıklarını ölçmek için Friborg ve ark. (2005) tarafından geliştirilen ve Basım ve Çetin (2011) tarafından Türkçe'ye uyarlanan "Psikolojik Dayanıklılık Ölçeği” kullanılmıştır. Çalışmamızda katılımcıların ölçekten aldıkları toplam puan değerlendirilmiştir. 5'li likert tipi olan ölçek toplam 33 sorudan oluşmaktadır. Ölçekteki soruların değerlendirilmesinde; 1, 3, 4, 8, 11, 12, 13, 14, 15, 16, 23, 24, 25, 27, 31, $33 \mathrm{nu-}$ maralı sorular ters soru, 2, 5, 6, 7, 9, 10, 17, 18, 19, 20, 21, 22, 26, 28, 29, 30, 32 numaralı sorular ise düz soru olarak değerlendirilmiştir. Ölçekten al1nan puanın yüksek olması kişinin psikolojik dayanıklılığının yüksek olduğunun göstergesidir. Ölçek 6 alt boyuttan olmak üzere toplam 33 sorudan oluşmaktadır. Alt boyutlar;

Kendilik algısl, kişinin kendi farkındalığına varmasını ve temelde kim olduğuna yönelik düşünceleri ifade etmektedir.

Gelecek algısı, bireyin geleceğe yönelik bakış açısına işaret etmenin yanı sıra, geleceğe yönelik olumlu bakış açısı psikolojik dayanıklılık sürecinde önemli rol oynamaktadır. 
Sosyal yeterlilik, bireyin sosyal adaptasyonunu, dişa dönüklüğünü ve sosyal aktivitelerde bulunma isteğini ifade eder.

Yapısal stil, bireyin günlük işlerini sürdürebilme, planlama ve organize edebilme yeteneği ile ilgilidir.

Aile uyumu, bireyin ailesinden gördüğü desteği belirtmektedir.

Sosyal kaynaklar, kişinin sahip olduğu sosyal ilişkileri göstermektedir (Çetin ve Basım,2011).

Çalışmamızın toplam puanlarına ilişkin hesaplanan Cronbach alfa iç tutarlılık kat sayısı değeri incelendiğinde 0.88 olarak görülmüştür. Ölçeğin toplam puan Cronbach değerlerine göre araştırmanın iç tutarlılığa sahip olduğu görülmektedir

\section{İstatistik}

Verilerin analizi SPSS 21 paket programı ile yapılmıştır. Verilerin normal dağılım gösterip göstermediği Kolmogorov-Smirnov testi ile bakılmış ve böylece verilerin normal dağılım göstermediği tespit edilmiştir $(p<0,05)$. Mann Whitney U testi kullanılmıştır. Anlamlılık düzeyi olarak iki grup karşılaştırılmasında 0.05 ve 0.01 değerleri alınmıştır.

\section{Bulgular}

Araştırmanın bu bölümünde araştırma kapsamında belirlenen problemlere yönelik yapılan analizlere ve bulgulara yer verilmiştir.

Tablo 1 de fakülte değişkenine göre psikolojik dayanıklılık ölçeği alt boyutları ve toplam puanları karşılaştırılmıştır. Aile uyumu, sosyal yeterlilik ve sosyal kaynaklar alt boyutlarında ve toplam puanda ilahiyat fakültesi öğrencilerinin puanlarının spor bilimleri fakültesi öğrencilerin puanından anlamlı düzeyde yüksek olduğu tespit edilmiştir $(\mathrm{p}<0.05)$. Ancak diğer alt boyutlarda gelecek algısı, kendilik algısı ve yapısal stil puanlarında fakülteye göre anlamlı farklılık tespit edilmemiştir ( $\mathrm{p}>0.05)$. 
Tablo 1. Öğrencilerin fakülte değişkenine göre psikolojik dayanıklılık puanlarının karşılaştırılması

\begin{tabular}{|c|c|c|c|c|c|c|c|}
\hline Alt Boyutlar & Fakülte & $\mathbf{N}$ & Ort & SS & Median & $U$ & $\mathbf{p}$ \\
\hline \multirow{2}{*}{ Gelecek Algısı } & SBF & 151 & 15.15 & 3.60 & 15 & \multirow{2}{*}{9691,50} & \multirow{2}{*}{0.037} \\
\hline & İLHYT & 149 & 15.98 & 3.17 & 16 & & \\
\hline \multirow{2}{*}{ Aile Uyumu } & SBF & 151 & 21.90 & 5.43 & 22 & \multirow{2}{*}{9073,00} & \multirow{2}{*}{0.004} \\
\hline & İLHYT & 149 & 23.71 & 4.54 & 24 & & \\
\hline \multirow{2}{*}{ Kendilik Algısı } & SBF & 151 & 23.27 & 4.72 & 23 & \multirow{2}{*}{10281,00} & \multirow{2}{*}{0.196} \\
\hline & İLHYT & 149 & 22.40 & 4.89 & 22 & & \\
\hline \multirow{2}{*}{ Sosyal Yeterlilik } & SBF & 151 & 21.52 & 4.36 & 21 & \multirow{2}{*}{9054,50} & \multirow{2}{*}{0.003} \\
\hline & İLHYT & 149 & 22.91 & 4.65 & 23 & & \\
\hline \multirow{2}{*}{ Sosyal Kaynaklar } & SBF & 151 & 26.63 & 5.39 & 23 & \multirow{2}{*}{8951,00} & \multirow{2}{*}{0.002} \\
\hline & İLHYT & 149 & 28.55 & 4.72 & 27 & & \\
\hline \multirow{2}{*}{ Yapisal Stil } & SBF & 151 & 14.33 & 3.60 & 29 & \multirow{2}{*}{10777,50} & \multirow{2}{*}{0.528} \\
\hline & İLHYT & 149 & 13.93 & 3.69 & 14 & & \\
\hline \multirow{2}{*}{ Toplam Puan } & SBF & 151 & 122.83 & 21.65 & 123 & \multirow{2}{*}{9652,00} & \multirow{2}{*}{0.033} \\
\hline & İLHYT & 149 & 127.44 & 17.82 & 130 & & \\
\hline
\end{tabular}

SBF= Spor Bilimleri Fakültesi $\quad$ ILHYT $=$ Ilahiyat

Tablo 2: Tüm öğrencilerin cinsiyet değişkenine göre psikolojik dayanıklılık ölçeği puanlarının karşılaştırılması

\begin{tabular}{|c|c|c|c|c|c|c|c|}
\hline Alt Boyutlar & Cinsiyet & $\mathbf{N}$ & Ort & SS & Median & $U$ & $\mathrm{p}$ \\
\hline \multirow{2}{*}{ Gelecek Algisı } & Kadın & 157 & 15.89 & 3.32 & 16 & \multirow{2}{*}{9588,00} & \multirow{2}{*}{0.028} \\
\hline & Erkek & 143 & 15.11 & 3.47 & 15 & & \\
\hline \multirow{2}{*}{ Aile Uyumu } & Kadın & 157 & 23.77 & 4.81 & 24 & \multirow{2}{*}{8658,00} & \multirow{2}{*}{0.001} \\
\hline & Erkek & 143 & 21.74 & 5.17 & 21 & & \\
\hline \multirow{2}{*}{ Kendilik Algısı } & Kadın & 157 & 22.35 & 4.88 & 22 & \multirow{2}{*}{10004,00} & \multirow{2}{*}{0.103} \\
\hline & Erkek & 143 & 23.34 & 4.71 & 24 & & \\
\hline \multirow{2}{*}{ Sosyal Yeterlilik } & Kadın & 157 & 23.07 & 4.32 & 23 & \multirow{2}{*}{8544,00} & \multirow{2}{*}{0.000} \\
\hline & Erkek & 143 & 21.27 & 4.63 & 21 & & \\
\hline \multirow{2}{*}{ Sosyal Kaynaklar } & Kadın & 157 & 28.50 & 4.87 & 29 & \multirow{2}{*}{8888,50} & \multirow{2}{*}{0.002} \\
\hline & Erkek & 143 & 26.58 & 5.28 & 27 & & \\
\hline \multirow{2}{*}{ Yapısal Stil } & Kadın & 157 & 14.14 & 3.75 & 15 & \multirow{2}{*}{10925,00} & \multirow{2}{*}{0.687} \\
\hline & Erkek & 143 & 14.12 & 3.55 & 14 & & \\
\hline \multirow{2}{*}{ Toplam Puan } & Kadın & 157 & 127.79 & 18.25 & 131 & \multirow{2}{*}{9360,00} & \multirow{2}{*}{0.013} \\
\hline & Erkek & 143 & 122.18 & 21.32 & 123 & & \\
\hline
\end{tabular}

Tablo 2 de tüm öğrencilerin cinsiyet değişkenine göre psikolojik dayanıklılık ölçeği alt boyutları ve toplam puanları karşılaştırılmıştır. Gelecek algısı, aile uyumu, sosyal yeterlilik, sosyal kaynaklar alt boyutlarında ve 
toplam puanlarında kadın öğrencilerin puanlarının erkek öğrencilerin puanından anlamlı düzeyde yüksek olduğu tespit edilmiştir $(\mathrm{p}<0.05)$. Ancak kendilik algısı ve yapısal stil alt boyutlarında cinsiyete göre anlamlı farklılık tespit edilmemiştir ( $\mathrm{p}>0.05)$.

Tablo 3. Öğrencilerin sigara veya alkol kullanma durumlarna göre psikolojik dayanıklılık ölçeği puanlarının karşılaştırılması

\begin{tabular}{|c|c|c|c|c|c|c|c|}
\hline $\begin{array}{l}\text { Alt } \\
\text { Boyutlar }\end{array}$ & $\begin{array}{l}\text { Sigara veya Alkol } \\
\text { Kullanma Durumu }\end{array}$ & $\mathbf{N}$ & Ort & SS & Median & $U$ & $\mathrm{p}$ \\
\hline \multirow{2}{*}{$\begin{array}{l}\text { Gelecek } \\
\text { Algisı }\end{array}$} & Evet & 105 & 15.18 & 3.30 & 15 & \multirow{2}{*}{9052,50} & \multirow{2}{*}{0.096} \\
\hline & Hayır & 195 & 15.77 & 3.47 & 16 & & \\
\hline \multirow{2}{*}{$\begin{array}{l}\text { Aile } \\
\text { Uyumu }\end{array}$} & Evet & 105 & 21.46 & 5.36 & 21 & \multirow{2}{*}{8017,50} & \multirow{2}{*}{0.002} \\
\hline & Hayır & 195 & 23.52 & 4.79 & 24 & & \\
\hline \multirow{2}{*}{$\begin{array}{l}\text { Kendilik } \\
\text { Algısı }\end{array}$} & Evet & 105 & 22.97 & 4.82 & 23 & \multirow{2}{*}{10050,00} & \multirow{2}{*}{0.793} \\
\hline & Hayır & 195 & 22.77 & 4.82 & 22 & & \\
\hline \multirow{2}{*}{$\begin{array}{l}\text { Sosyal } \\
\text { Yeterlilik }\end{array}$} & Evet & 105 & 21.81 & 4.52 & 21 & \multirow{2}{*}{9346,00} & \multirow{2}{*}{0.212} \\
\hline & Hayır & 195 & 22.43 & 4.57 & 22 & & \\
\hline \multirow{2}{*}{$\begin{array}{l}\text { Sosyal } \\
\text { Kaynaklar }\end{array}$} & Evet & 105 & 26.84 & 5.11 & 27 & \multirow{2}{*}{8888,50} & \multirow{2}{*}{0.059} \\
\hline & Hayır & 195 & 27.98 & 5.14 & 29 & & \\
\hline \multirow{2}{*}{$\begin{array}{l}\text { Yapisal } \\
\text { Stil }\end{array}$} & Evet & 105 & 13.73 & 3.56 & 14 & \multirow{2}{*}{9258,00} & \multirow{2}{*}{0.170} \\
\hline & Hayır & 195 & 14.35 & 3.68 & 14 & & \\
\hline \multirow{2}{*}{$\begin{array}{l}\text { Toplam } \\
\text { Puan }\end{array}$} & Evet & 105 & 122.01 & 20.93 & 123 & \multirow{2}{*}{8716,00} & \multirow{2}{*}{0.034} \\
\hline & Hayır & 195 & 126.79 & 19.24 & 128 & & \\
\hline
\end{tabular}

Tablo 3 te spor bilimleri ve ilahiyat fakültesinde okuyan öğrencilerin sigara veya alkol kullanma durumu değişkenine göre psikolojik dayanıklılık ölçeği alt boyutları ve toplam puanları karşılaştırılmıştır. Aile uyumu ve sosyal kaynaklar alt boyutlarında ve toplam puanlarında sigara veya alkol kullanmayan öğrencilerin puanlarının kullanan öğrencilerin puanından anlamlı düzeyde yüksek olduğu tespit edilmiştir $(\mathrm{p}<0.05)$. Ancak gelecek alg1sı, kendilik algısı, sosyal yeterlilik ve yapısal stil alt boyutları puanlarında sigara veya alkol kullanma durumlarına göre anlamlı farkl1lik tespit edilmemiştir ( $\mathrm{p}>0.05)$.

Tablo 4 te spor bilimleri ve ilahiyat fakültesinde okuyan öğrencilerin düzenli spor yapma durumu değişkenine göre psikolojik dayanıklılık ölçeği alt boyutları ve toplam puanları karşılaştırılmıştır. Düzenli spor yapma durumuna göre gelecek alg1sı, aile uyumu, sosyal yeterlilik, sosyal kaynaklar, yapısal stil alt boyutları ve toplam puanlarının farklılaşmadığı tespit edilmiştir ( $p>0.05)$. Ancak kendilik algısı alt boyut puanında düzenli 
spor yapanların puanlarının yapmayanlardan daha yüksek olduğu tespit edilmiştir $(\mathrm{p}<0.05)$.

Tablo 4. Öğrencilerin düzenli spor yapma durumuna göre psikolojik dayanıklılı ölçeği puanlarının karşılaş̧tırılması

\begin{tabular}{|c|c|c|c|c|c|c|c|}
\hline Alt Boyutlar & $\begin{array}{l}\text { Düzenli Spor } \\
\text { Yapma Durumu }\end{array}$ & $\mathbf{N}$ & Ort & ss & Median & $u$ & p \\
\hline \multirow{2}{*}{$\begin{array}{l}\text { Gelecek } \\
\text { Algisı }\end{array}$} & Evet & 156 & 15.37 & 3.64 & 15 & \multirow{2}{*}{10524,00} & \multirow{2}{*}{0.342} \\
\hline & Hayır & 144 & 15.77 & 3.15 & 16 & & \\
\hline \multirow{2}{*}{ Aile Uyumu } & Evet & 156 & 22.25 & 5.14 & 22 & \multirow{2}{*}{9794,50} & \multirow{2}{*}{0.055} \\
\hline & Hayır & 144 & 23.39 & 4.97 & 23 & & \\
\hline \multirow{2}{*}{$\begin{array}{l}\text { Kendilik } \\
\text { Algısı }\end{array}$} & Evet & 156 & 23.58 & 4.58 & 24 & \multirow{2}{*}{9319,00} & \multirow{2}{*}{0.011} \\
\hline & Hayır & 144 & 22.04 & 4.95 & 22 & & \\
\hline \multirow{2}{*}{$\begin{array}{l}\text { Sosyal } \\
\text { Yeterlilik }\end{array}$} & Evet & 156 & 21.83 & 4.52 & 22 & \multirow{2}{*}{10116,50} & \multirow{2}{*}{0.136} \\
\hline & Hayır & 144 & 22.63 & 4.56 & 23 & & \\
\hline \multirow{2}{*}{$\begin{array}{l}\text { Sosyal } \\
\text { Kaynaklar }\end{array}$} & Evet & 156 & 27.20 & 5.25 & 28 & \multirow{2}{*}{10281,50} & \multirow{2}{*}{0.204} \\
\hline & Hayır & 144 & 28.00 & 5.03 & 28 & & \\
\hline \multirow{2}{*}{ Yapısal Stil } & Evet & 156 & 14.51 & 3.72 & 14 & \multirow{2}{*}{9918,00} & \multirow{2}{*}{0.079} \\
\hline & Hayır & 144 & 13.72 & 3.53 & 14 & & \\
\hline \multirow{2}{*}{ Toplam Puan } & Evet & 156 & 124.77 & 20.73 & 125 & \multirow{2}{*}{10894,50} & \multirow{2}{*}{0.653} \\
\hline & Havır & 144 & 125.50 & 19.12 & 127 & & \\
\hline
\end{tabular}

\section{Tartışma}

Çalışmamızda İlahiyat Fakültesi ve Spor Bilimleri Fakültesi öğrencilerinin psikolojik dayanıklılık ölçeği alt boyutları ve toplam puanları karşılaştırılmasında, fakülte değişkenine göre aile uyumu, sosyal yeterlilik ve sosyal kaynaklar alt boyutlarında ve toplam puanlarında anlamlı farklılık tespit edildi. İlahiyat fakültesi öğrencilerinin aile uyumu, sosyal yeterlilik ve sosyal kaynaklar alt boyut ve toplam puanlarının spor bilimleri fakültesi öğrencilerinden daha yüksek olduğu saptandı. Ancak diğer alt boyutlarda gelecek algısı, kendilik algısı ve yapısal stil puanlarında fakülteye göre anlamlı farklılık tespit edilmedi. Dolayısıyla çalışmamız sonuçlarına göre ilahiyat fakültesi öğrencilerinin psikolojik dayanıklılık düzeylerinin spor bilimleri fakültesi öğrencilerine göre daha iyi olduğu söylenebilir. Din, insanın anlam arayışında önemli bir yer tutan, yaşamın anlamını oluşturan önemli kaynaklardan biridir. İnsanların hayata daha olumlu bir şekilde tutunmalarına yardım ederek hayatı ve yaptıkları işleri daha anlamlı kılmaktadır (Karaca, 2015, s.111). Bu yönüyle din, insanlara hayatlarında zor ve olumsuz görünen durum ve olayların olumlu yönlerini fark etmelerini 
sağlayarak psikolojik sağlamlıklarını arttırıcı bir faktör olarak düşünülebilir (Sezgin 2016).

Literatür bulguları incelendiğinde çalışmamız sonuçlarını destekleyen ve aksini belirten çalışmaların olduğu tespit edildi. Örneğin, Sezgin (2016) araştırmasında öğrencilerin öğrenim gördükleri fakülteye göre psikolojik sağlamlık düzeylerinde anlamlı bir farklılık olmadığını saptamıştır. Yine aynı şekilde Eryılmaz'ın (2012) üniversite öğrencilerinin psikolojik sağlamlıklarını incelediği çalışmada da öğrencilerin öğrenim gördükleri fakülte değişkenine göre psikolojik sağlamlık düzeylerinde anlamlı bir farklılık tespit etmemiştir. Atarbay (2017) çalışmasında üniversite öğrencilerinin öğrenim görmekte olduğu lisans programlarının psikolojik dayanıkl1lık gücüne anlamlı bir etkisi bulunmadığı sonucuna ulaşmıştır. Gürgan (2014) araştırmasında ise üniversite öğrencilerinin yılmazlık puanları bölüm değişkenine göre anlamlı bir farklılık gösterdiği sonucuna ulaşmıştır.

Çalışmamızda tüm öğrencilerin psikolojik dayanıklılık ölçeği alt boyut ve toplam puanlarının cinsiyete göre istatistiksel olarak karşılaştırılmasında, kadın öğrencilerin gelecek algısı, aile uyumu, sosyal yeterlilik, sosyal kaynaklar alt boyut ve toplam puanlarının erkek öğrencilerin puanından anlamlı düzeyde yüksek olduğu tespit edildi. Ancak kendilik algısı ve yapısal stil alt boyutlarında cinsiyete göre anlamlı farklılık tespit edilmedi. Dolayısıyla çalışmamız sonuçlarına göre cinsiyet değişkeninin psikolojik dayanıklılığa etkisi olduğu söylenebilir. Literatür bulguları incelendiğinde konuyla ilgili yapılan çalışmaların sonuçları çalışmamızın bulgusunu desteklemektedir (Önder ve Gülay 2008; Oktan 2008; Kılıç 2014; Bülbül 2015; Güngörmüş ve ark., 2015; Gündaş ve Koçak 2015; Kahraman 2016; İçel ve Özkan 2018). Bununla beraber çalışmamız bulgularının sonuçlarını desteklemeyen çalışmalarda mevcuttur (Terzi, 2008; Bahadır, 2009; Erdoğan 2015; Sezgin 2016, Aydın ve Egemberdiyeva 2018).

İçel ve Özkan (2018) çalışmalarında psikolojik dayanıklılık puanları cinsiyete göre değerlendirildiğinde kı öğrencilerin psikolojik dayanıkl1lık düzeyleri erkek öğrencilere göre istatistiksel olarak anlamlı derecede yüksek olduğunu tespit etmişlerdir. Yine Kılıç (2014), çalışmasında üniversite öğrencilerinin cinsiyetleri ile psikolojik dayanıklılıkları arasında anlamlı bir farklılaşma tespit etmiş ve kızların puan ortalamalarının erkeklerden daha yüksek olduğunu tespit etmiştir. Güngörmüş ve ark, (2015), Önder ve Gülay (2008) ve Oktan (2008), yaptıkları çalışmalarında 
kız öğrencilerin psikolojik dayanıklılık düzeylerinin erkek öğrencilerden anlamlı derecede yüksek olduğunu tespit etmişlerdir. Sezgin (2016), araştırmasında üniversite öğrencilerinin cinsiyetlerine göre psikolojik sağlamlık düzeylerinde erkeklerin psikolojik sağlamlık düzeylerinin kadınların psikolojik sağlamlık düzeylerinden anlamlı derecede yüksek olduğunu tespit etmiştir. Bu durumu da geleneksel aile yapısı içinde yetişen erkeklerin kadınlara oranla aile içinde daha çok sorumluluk almalarıyla stres durumları ve problem çözmede daha güçlü olmalarından kaynaklanabileceğini belirtmiştir.

Çalışmamızda tüm öğrencilerin psikolojik dayanıklılık ölçeği alt boyut ve toplam puanları sigara veya alkol kullanma durumlarına göre istatistiksel olarak karşılaştırılmasında, sigara veya alkol kullanmayan öğrencilerin aile uyumu, sosyal kaynaklar alt boyut ve toplam puanlarının sigara veya alkol kullanan öğrencilerin puanından anlamlı düzeyde yüksek olduğu tespit edildi. Yani sigara veya alkol kullanmayan öğrencilerin psikolojik dayanıklılık puanlarının daha yüksek olduğu saptandı. Çalışmamız sonuçlarına göre sigara veya alkol kullanmanın psikolojik dayanıklılığa olumsuz etkisi olduğu söylenebilir.

Çalışmamızda öğrencilerin düzenli spor yapma durumuna göre psikolojik dayanıklılık ölçeği alt boyutları ve toplam puanlarının karşılaştırılmasında, düzenli olarak spor yapma durumuna göre sadece kendilik algisı alt boyutunda öğrencilerin psikolojik dayanıklılık puanlarının anlamlı bir şekilde farklılaştığ tespit edildi. Ancak diğer tüm alt boyut ve toplam psikolojik dayanıklılık puanların düzenli spor yapma durumuna göre farklılaşmadığı görüldü.

\section{Sonuç ve Öneriler}

İlahiyat Fakültesi öğrencilerinin Spor Bilimleri Fakültesi öğrencilerine göre psikolojik dayanıklılıkları daha yüksektir. Sigara ve alkol kullanımı kişinin psikolojik dayanıklılık düzeyini olumsuz etkilemektedir. Ayrıca kadınların psikolojik dayanıklılıkları erkeklere göre daha yüksektir. Kişilerin psikolojik dayanıklılık düzeylerinin yükseltilmesi dolayısıyla zorluklara veya olumsuz durumlara karşı başarılı şekilde baş edebilmelerini sağlamaları için gerekli desteklerin, eğitimlerin, seminerlerin düzenlenmesi önerilebilir. 


\title{
EXTENDED ABSTRACT
}

\section{Comparison of Psychological Resilience Levels of Faculty of Sport Sciences and Faculty of Theology Students}

\author{
* \\ Tülin Atan - Şaban Ünver \\ Samsun Ondokuz Mayıs University
}

Psychological Resilience is defined as one's adaptation process to a trauma, threat, tragedy or familial problems, serious health problems, important sources of stress, such as workplace and financial problems, his ability to self-heal and successfully overcome difficulties. It is also addressed with different names, such as psychological sturdiness or the ability to self-heal. (Gürgan 2010; Karaırmak 2006; Basım and Çetin 2011). Psychological sturdiness is defined as being able to return to normal functioning successfully despite severe adaptation and development threats and difficult living conditions (Masten, 2001). Psychological Resilience is a multidimensional concept defined as an individual's being flexible in reacting to changing situations and self-recovering from negativity with emotional experiences (Tugade and Fredrickson, 2004).

If we are to make a definition by using this information, psychological resilience appears to be the ability to cope with a problem or difficulty when they are faced. Sports, which emerges as a multidimensional phenomenon in the social field, has a very important position in the development of healthy individuals with their individual, economic and social aspects, in the protection of public health, development of the economy, establishment of social peace and in the development of interpersonal harmony. Therefore, the aim of this study is to compare the psychological resilience levels of university students studying at the faculty of sports sciences with the ones studying at the faculty of theology in the context of faculty and some variables. 
A total of 300 students studying at Ondokuz Mayıs University, the faculty of sports sciences $(n=151)$ whose age average was $22,12 \pm 2.33$ years and studying at the faculty of theology $(n=149)$ whose age average was of was 20,86 \pm 2.44 years participated as volunteers in this study.

In the study, as data collection tool, Demographic Information Form developed by the researchers and to measure the psychological resilience of the students of sports sciences and the faculty of theology, Psychological Resilience Scale developed by Friborg et al. (2005), adapted into Turkish by Basım and Çetin (2001) was made use of. In our study, the total score of participants they got from the scale was evaluated. The 5 point likert scale consists of a total of 33 questions. In the evaluation of the questions in the scale; Questions 1, 3, 4, 8, 11, 12, 13, 14, 15, 16, 23, 24, 25, 27, 31, 33 were considered as inverse question, while Questions 2, 5, 6, 7, 9, 10, $17,18,19,20,21,22,26,28,29,30,32$ as straight. The high score obtained from the scale indicates that the psychological resilience of the person is high. The scale consists of a total of 33 questions including 6 sub-dimensions (Perception of self, Perception of Future, Social competence, Structural style, Family harmony, Social resources) (Çetin and Basım 2011).

The Cronbach alpha internal consistency coefficient value calculated relating to the total scores of our study appeared as 0.88 . According to the total score Cronbach values of the scale, the study has internal consistency. Data were analyzed using SPSS 21 software. Whether data showed normal distribution or not was determined by the Kolmogorov-Smirnov test, and it was found that the data did not show normal distribution $(\mathrm{p}<0.05)$. The Mann Whitney $\mathrm{U}$ test was used. The values of 0.05 and 0.01 were taken for comparison of two groups as a level of significance.

In our study, in the comparison of psychological resilience scale subdimensions and total scores of the students of faculty of theology and the students of the faculty of sports sciences, a significant difference was found in the sub-dimensions and total scores of family harmony, social competence and social resources in terms of faculty variable. The sub-dimensions and total scores of family harmony, social competence and social resources of the students of the faculty of theology were detected to be higher than the ones of the students of the faculty of sports sciences. However, in the other sub-dimensions, there was no significant difference in terms of faculty in the scores of perception of future, perception of self, 
and structural style. Therefore, according to the results of our study, it can be said that the psychological resilience levels of the faculty of theology students are better compared to the ones of the sports sciences faculty students.

In our study, in the statistical comparison of all students' sub-dimension and total scores of psychological resilience scale in terms of gender, it was found that the sub-dimension and total scores of female students' perception of future, family harmony, social competence, social resources were significantly higher than the score of male students. However, no significant differences were found in the sub-dimensions of perception of self and structural style in terms of gender. Therefore, according to the results of our study, it can be said that the gender variable has an effect on psychological resilience.

In our study, in the statistical comparison of all students' sub-dimension and total scores of psychological resilience scale in terms of smoking or alcohol use status, it was found that the sub-dimension and total scores of family harmony and social resources of the students who did not use cigarettes or alcohol were significantly higher than the students who did. In other words, it was determined that the psychological resilience scores of the students who did not use cigarettes or alcohol were higher. According to the results of our study, it can be said that smoking or alcohol use has a negative effect on psychological resilience.

In our study, in the comparison of students' sub-dimension and total scores of psychological resilience scale in terms of regular physical exercise, it was found that only in the perception of self sub-dimension, the students' psychological resilience score differed significantly. However, the scores of all other sub-dimensions and total psychological resilience did not differentiate in terms of regular physical exercise.

Women compared to men; faculty of theology students compared to faculty of sports sciences students have higher levels of psychological resilience. Smoking and alcohol use have a negative effect on the individual's psychological resilience level. It may be recommended to arrange the necessary supports, training, and seminars in order to enable people to cope with difficulties or adverse situations by increasing their level of psychological resilience. 


\section{Kaynakça / References}

Atarbay, S. (2017). Farklı bölümlerde öğrenim gören üniversite öğrencilerinin sosyal kaygı düzeylerinin psikolojik dayanıklılklarına etkisi. Yüksek Lisans Tezi, İstanbul Üniversitesi Eğitim Bilimleri Enstitüsü, İstanbul.

Aydın, M. ve Egemberdiyeva, A. (2018). Üniversite öğrencilerinin psikolojik sağlamlık düzeylerinin incelenmesi. Türkiye Eğitim Dergisi, 3(1), 37-53.

Bahadır, E. (2009). Sağllkla ilgili fakültelerde eğitime başlayan öğrencilerin psikolojik sağlamlık düzeyleri. Yüksek Lisans Tezi, Hacettepe Üniversitesi, Sağlık Bilimleri Enstitüsü. Ankara

Basım H.N. ve Çetin, F. (2011). Yetişkinler için psikolojik dayanıklılık ölçeğinin güvenilirlik ve geçerlilik çalışması. Türk Psikiyatri Dergisi, 22, 104114.

Bülbül, A. (2015). Tenis ve basketbol sporcularmnn psikolojik dayanıklllk seviyelerinin incelenmesi ve karşılaştırılması. Yüksek Lisans Tezi, Gediz Üniversitesi, Sağlık Bilimleri Enstitüsü, İstanbul.

Doğan, T. (2015). Kısa psikolojik sağlamlık ölçegi'nin Türkçe uyarlaması: Geçerlik ve güvenirlik çalışması, The Journal Of Happiness and Well- Being, 3(1), 93-102.

Erdoğan, E. (2015). Tanrı algısı, dini yönelim biçimleri ve öznel dindarlığın psikolojik dayanıklılıkla ilişkisi: üniversite örneklemi. Mustafa Kemal Üniversitesi Sosyal Bilimler Enstitüsü Dergisi, 12(29), 223-246.

Eryılmaz, S. (2012). Üniversite öğrencilerinde psikolojik sağlamlığı yordamada, yaşam doyumu, benlik saygısı, iyimserlik ve kontrol odağının incelenmesi. Yüksek Lisans Tezi, Muğla Üniversitesi, Eğitim Bilimleri Enstitüsü. Muğla

Friborg, O, Barlaug, D. Martinussen, M. Rosenvinge, J.H. ve Hjemdal, O. (2005). Resilience in relation to personality and intelligence. Int J Methods Psychiatr Res, 14(1), 29-42.

Gizir, C.A. (2007). Psikolojik sağlamlık, risk faktörleri ve koruyucu faktörler üzerine bir derleme çalışması. Türk Psikolojik Danışma ve Rehberlik Dergisi, 28, 113-128.

Gündaş, A. ve Koçak, R. (2015). Lise öğrencilerinde psikolojik sağlamlığın yordayıcısı olarak benlik kurgusu. Uluslararası Sosyal Araştırmalar Dergisi, 8(41), 795-802.

Güngörmüş, K. Okanll, A. ve Kocabeyoğlu, T. (2015). Hemşirelik öğrencilerinin psikolojik dayanıklılıkları ve etkileyen faktörler. Psikiyatri Hemşireliği Dergisi, 6(1), 9-14. 
Gürgan, U. (2010). Yılmazlık Ölçeği (YÖ): Ölçek geliştirme, güvenirlik ve geçerlik çalışması. Ankara Üniversitesi Ĕ̆itim Bilimleri Fakültesi Özel Ĕ̆gitim Dergisi, 11, 47-62.

Gürgan, U. (2014). Üniversite öğrencilerinin yılmazlık ve iyilik halinin bazı değişkenlere göre incelenmesi. NWSA-Education Sciences, 9(1), 18-35.

Hefferon, K. ve Boniwell, I. (2011). Positive psychology: Theory, Research and applications. Open University Press, NY.

İçel, S. ve Özkan, B. (2018). Sağlık Yüksekokulu hemşirelik öğrencilerinin psikolojik dayanıklılıklarının incelenmesi. Akademik Sosyal Araştırmalar Dergisi, 6(73), 240-251.

Kahraman, N. (2016). Kamu ă̆ız ve diş sağlığı merkezi çalışanlarının psikolojik dayanıklılı düzeyleri:Ankara İli örneği. Yüksek Lisans Tezi, Gazi Üniversitesi Sosyal Bilimler Enstitüsü, Ankara.

Karaca, F. (2015). Din psikolojisi. Trabzon: Eser Ofset Matbaacilık.

Karaırmak, Ö. (2006). Psikolojik sağlamlık, risk faktörleri ve koruyucu faktörler. Türk Psikolojik Danışma ve Rehberlik Dergisi, 26, 129-142.

Kılıç, Ş. (2014). Üniversite öğrencilerinin yalnızlık ve psikolojik dayanıklılıklarının incelenmesi. Yüksek Lisans Tezi, Atatürk Üniversitesi Eğitim Bilimleri Enstitüsü, Erzurum.

Masten, A.S. (2001). Ordinary magic: Resilience Processes in development. American Psychologist, 56(3), 227-238.

Oktan, V. (2008). Üniversite sınavına hazırlanan ergenlerin psikolojik sağlamlıklarının çeşitli değişkenlere göre incelenmesi. Yayınlanmamış Doktora Tezi, Karadeniz Teknik Üniversitesi Sosyal Bilimler Enstitüsü, Trabzon.

Önder, A. ve Gülay, H. (2008). İlköğretim 8.sınıf öğrencilerinin psikolojik sağlamlığının çeşitli değişkenler açısından incelenmesi. Dokuz Eylül Üniversitesi Buca Eğitim Fakültesi Dergisi, 23, 192-197.

Sezgin, K. (2016). Üniversite öğrencilerinin psikolojik sağlamlık ve dindarlık düzeylerinin incelenmesi: Dicle Üniversitesi örneği. Yüksek Lisans Tezi, Dicle Üniversitesi Sosyal Bilimler Enstitüsü, Diyarbakır.

Terzi, Ş. (2008). Üniversite öğrencilerinin psikolojik dayanıklılıkları ve algıladıkları sosyal destek arasındaki ilişki. Türk Psikolojik Danışma ve Rehberlik Dergisi, 3(29), 1-11.

Tugade, M.M. ve Fredrickson, B.L. (2004). Resilient individuals use emotions to bounce back from negative emotional experiences. Journal of Personality and Social Psychology, 86(2), 320-333. 


\section{Kaynakça Bilgisi / Citation Information}

Atan, T. ve Ünver, Ş. (2019). Spor bilimleri fakültesi ve ilahiyat fakültesi öğrencilerinin psikolojik dayanıklılık düzeylerinin karşılaş-tırılması. OPUS-Uluslararası Toplum Araştırmaları Dergisi, 14(20), 207222. DOI: $10.26466 /$ opus. 567468 